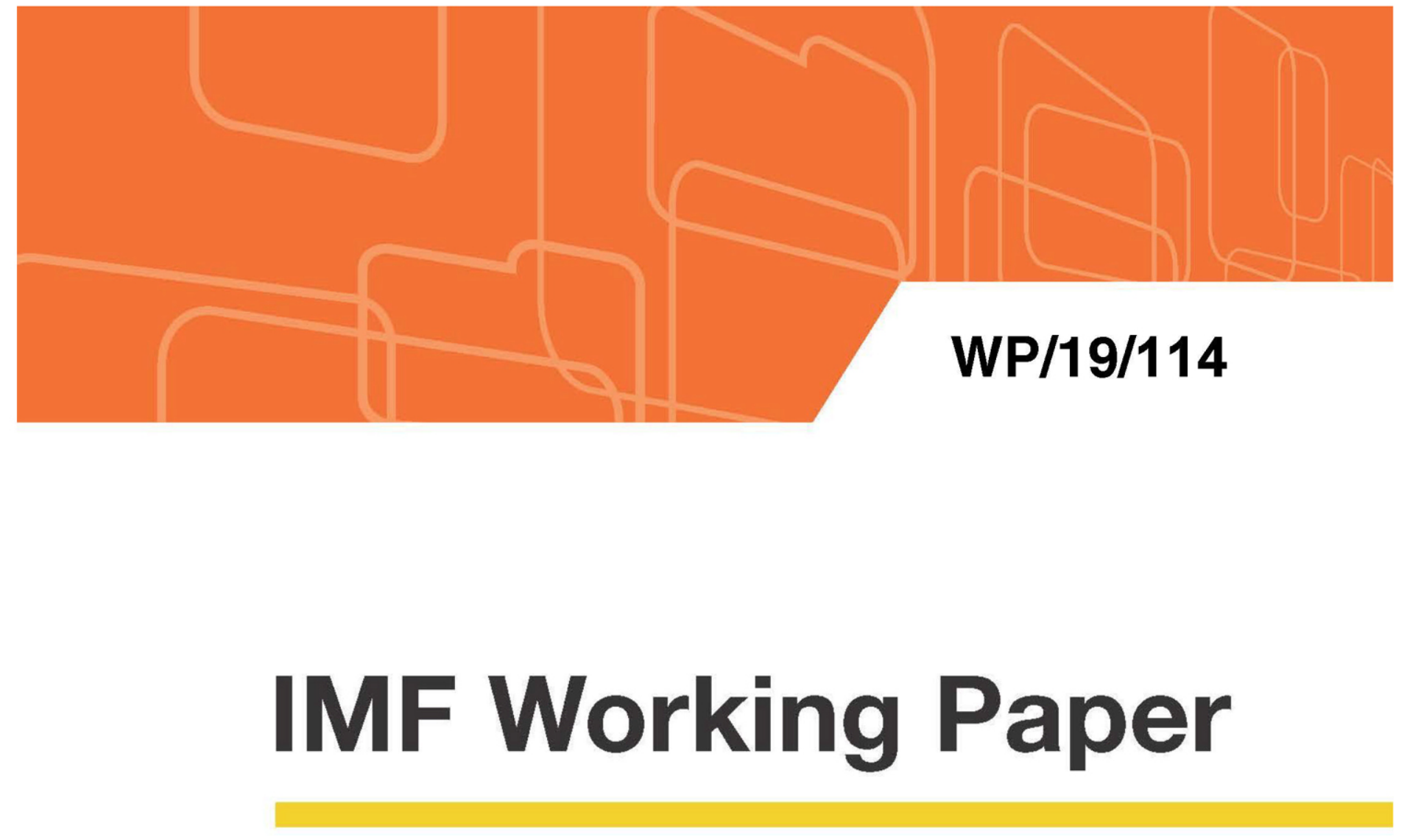

\title{
Hysteresis in Labor Markets? \\ Evidence from Professional Long-Term Forecasts
}

by John Bluedorn and Daniel Leigh

IMF Working Papers describe research in progress by the author(s) and are published to elicit comments and to encourage debate. The views expressed in IMF Working Papers are those of the author(s) and do not necessarily represent the views of the IMF, its Executive Board, or IMF management.

$$
\text { I N T E R N A T I O N A L M O N E T A R Y F U N D }
$$




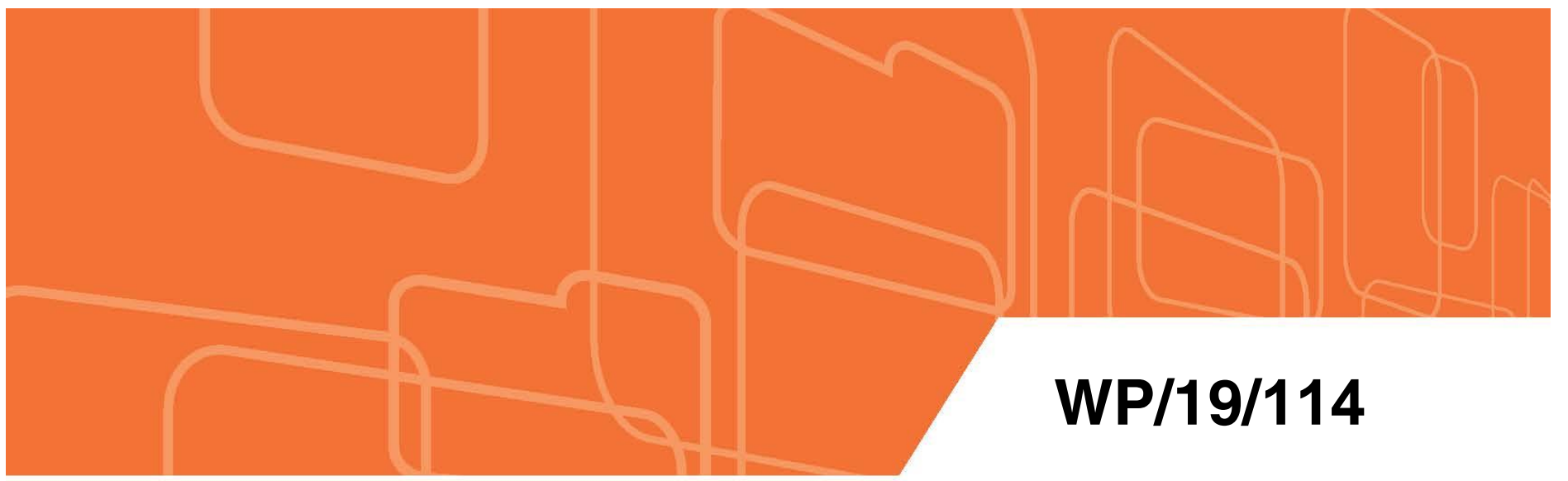

\section{IMF Working Paper}

\section{Hysteresis in Labor Markets? \\ Evidence from Professional Long-Term Forecasts}

by John Bluedorn and Daniel Leigh

IMF Working Papers describe research in progress by the author(s) and are published to elicit comments and to encourage debate. The views expressed in IMF Working Papers are those of the author(s) and do not necessarily represent the views of the IMF, its Executive Board, or IMF management.

$$
\text { I N T E R N A T I O N A L M O N E T A R Y F U N D }
$$




\title{
IMF Working Paper
}

Western Hemisphere Department and Research Department

\section{Hysteresis in Labor Markets? Evidence from Professional Long-Term Forecasts}

\section{Prepared by John Bluedorn and Daniel Leigh ${ }^{1}$}

Authorized for distribution by Nigel Chalk and Oya Celasun

May 2019

\section{IMF Working Papers describe research in progress by the author(s) and are published to elicit comments and to encourage debate. The views expressed in IMF Working Papers are those of the author(s) and do not necessarily represent the views of the IMF, its Executive Board, or IMF management.}

\begin{abstract}
We explore the long-term impact of economic booms on labor market outcomes using a novel approach based on revisions to professional forecasts over the past 30 years for 34 advanced economies. We find that when employment rises unexpectedly, forecasters typically raise their long-term forecasts of employment by more than one-for-one and also expect a strong rise in labor force participation, suggesting more persistent effects than is traditionally assumed. Economic booms associated with changes in aggregate demand, when inflation is rising and unemployment falling unexpectedly, also come with persistent long-term effects on expected employment and labor force participation, suggesting positive hysteresis. Our forecast evaluation tests indicate that forecasters are, on average, unbiased in their assessment of these positive, persistent effects.
\end{abstract}

JEL Classification Numbers: E32, E65, E66

Keywords: Hysteresis, business cycles, monetary policy.

Author’s E-Mail Address: JBluedorn@imf.org; DLeigh@imf.org

\footnotetext{
${ }^{1}$ We are grateful to Laurence Ball, Nigel Chalk, and numerous George Washington University and IMF seminar participants for helpful comments, and to Javier Ochoa for superb editorial support.
} 
The U.S. unemployment rate has fallen to its lowest level since the late 1960s amid rapid employment growth and moderate inflation. This has occurred in the context of strong aggregate demand conditions. However, there is no consensus on how long-lasting these labor market gains will be.

Traditional economic models imply that activity typically returns to its previous trend following booms, with only transitory effects on labor market outcomes. These predictions though can be overturned if other mechanisms are at work. Economic booms might attract previously discouraged workers back into the labor force, encourage efficiency-enhancing job switches, and prompt more investment into physical capital, training, and research and development, implying long-term supply-side effects, as Yellen (2016) and Blanchard (2018) explain. In an early contribution, Okun (1973) argued that a benefit of running a "high-pressure economy" with a tighter labor market was the greater human capital investment obtained from employment (through on-the-job training and experience), which could boost the economy's potential over the longer term. The notion that economic booms can have lasting effects on the supply-side of the economy is referred to as "positive hysteresis." "However, as Powell (2018) notes, the persistence of such positive hysteresis effects remains uncertain based on the historical record.

Assessing the long-term effects on labor market outcomes of historical economic fluctuations is hampered by methodological difficulties. Empirical studies typically rely on strong functional form assumptions for the underlying dynamic processes, estimating univariate ARMA, unobserved components, or other nonlinear parametric models to infer the persistence properties of output and employment. When structural breaks are pervasive and uncertain, the associated functional form assumptions may lead to a distorted picture of long-term labor market persistence. Moreover, identifying the relationship between current and far-future conditions is complicated by the inevitable accumulation of additional shocks, which may swamp the current shock's effects. Small sample sizes further exacerbate the difficulties of estimating long-horizon effects.

This paper proposes a way of dealing with these difficulties by using data on revisions to longterm forecasts of labor market variables made by professional forecasters in real time. We use historical data for long-term forecasts to identify forecasters' perceptions of the persistence of fluctuations in labor market variables, including employment, labor force participation, and the unemployment rate. As explained in Section I, if forecasters view labor market fluctuations as dominated by purely transitory fluctuations, an unexpected revision to a labor market variable today should bear no relationship to its expected level over long horizons. Our approach is close to that of Bluedorn and Leigh (2018) who conduct such tests for real GDP. We focus on IMF staff forecasts of labor market variables over five-year-ahead horizons from historical vintages of the IMF World Economic Outlook (WEO) database from the Spring and Fall of every year from 1990 through 2018 for 34 advanced economies (AEs).

\footnotetext{
${ }^{2}$ In the literature, the term hysteresis usually denotes the notion that recessions have permanent negative effects on the supply-side of the economy. Numerous studies since the global financial crisis find that the long-term costs of recessions are larger than traditionally assumed, suggesting hysteresis. See Ball 2009 and 2014; Erceg and Levin 2014; Blanchard, Cerutti, and Summers 2015; Martin, Munyan, and Wilson 2015; Fatás and Summers 2017; and Yagan 2018. More recently, a number of studies explore how economic booms affect labor market outcomes of various demographic groups, finding some evidence of positive hysteresis. See, for example, Hotchkiss and Moore 2018, and Aaronson and others 2019.
} 
Our estimation results indicate that forecasters view an employment expansion as typically having long-lasting effects. Following a 1 percent unexpected increase in current-period employment, the forecast of employment in five years rises by an average of 1.6 percent in the same direction. The forecast of labor force participation rises by 1.1 percent and the forecast of the unemployment rate falls by 0.4 percentage point. The magnitude of these results is economically significant and not consistent with the view that economic fluctuations typically have transitory effects. The results hold up to a battery of robustness checks, including the exclusion of extreme observations from the estimation sample and the inclusion of additional control variables in the model specification. The findings hold for all major AEs considered individually. They also hold for other available sources of labor market forecasts, such as the long-range forecasts of the U.S. Congressional Budget Office (CBO).

In Section II, we extend our analysis to shed light on the long-term effects of changes in aggregate demand. A standard implication of New Keynesian economic models is that positive shocks to aggregate demand induce a short-term trade-off between unemployment and inflation but have no long-term effects on economic activity, in line with Friedman's (1968) natural rate hypothesis. Accordingly, we focus on historical cases where current-period unemployment and inflation forecasts are revised in opposite directions. We define such episodes as dominated by shocks to aggregate demand. Our results suggest that forecasters view such episodes as having long-lasting effects on employment, labor force participation, and the unemployment rate. For each 1 percent surprise in current-period employment in demand-driven expansions, the five-year-ahead forecast of employment rises by an average of 1.7 percent; the five-year-ahead forecast of labor force participation rises by 1.3 percent; and the five-year ahead forecast of the unemployment rate is 0.4 percentage point lower. The near-term forecast of inflation rises in these episodes by an average of 0.2 percentage point (consistent with a Phillips Curve slope of about one-half) but expectations of inflation in 3-5 years are typically unaffected. Similar results hold in episodes featuring large unexpected changes in government consumption.

In Section III, we investigate what these results about forecasters' perceptions of persistence tell us about the actual persistence of labor market outcomes. If forecasters' views of long-term labormarket persistence are, on average, unbiased, then our approach sheds light on actual labor market persistence. We test this assumption based on a forecast efficiency test along the lines of Blanchard and Leigh (2014), also used in Bluedorn and Leigh (2018). If forecasters systematically overstate the persistence of an employment expansion, then subsequent forecast errors should be negatively correlated with the initial revision (similarly, if they understate, then the correlation would be positive). We find no evidence of such a systematic correlation-forecasters appear to neither over- nor understate the persistence of shocks. This finding holds in both the full sample, and when we focus on the afore-mentioned episodes associated with demand-driven shocks. Our results thus shed light on both the nature of expectations formation - the subject of a growing literature including studies by Krane (2011) and Coibion, Gorodnichenko, and Kamdar (2018) — and on the actual long-run effects of economic fluctuations on real outcomes.

Overall, these results are consistent with the positive hysteresis hypothesis and not consistent with the hypothesis that aggregate supply is independent of changes in aggregate demand. Section IV concludes by discussing implications for monetary policy. 


\section{ESTIMATION RESULTS}

\section{A. Baseline specification}

To investigate whether forecasters view labor market fluctuations as typically transitory, we regress the revision in the forecast for the level of labor market variables in year $t+5$ on the revision to the forecast for employment in year $t$. If forecasters view labor market fluctuations as dominated by transitory fluctuations, an unexpected change in employment today should have little effect on forecasts of the level of labor market outcomes over the medium term. For example, following an unexpected rise in employment in year $t$, forecasters should revise down growth for employment in subsequent years, ensuring that employment returns to its previous trend.

We estimate the following baseline equation for (log) employment, $e$, and then extend the approach to other labor market variables:

$$
r_{t}\left(e_{i, t+h}\right)=\alpha+\beta_{h} r_{t}\left(e_{i, t}\right)+\varepsilon_{h, i, t}
$$

where $e_{i, t+h}$ denotes the level of employment in economy $i$ in $h$ years and the associated forecast revision is $r_{t}\left(e_{i, t}\right)=f_{t}\left(e_{i, t}\right)-f_{t-1}\left(e_{i, t}\right)$, where $f_{t}$ denotes the forecast conditional on the information set available in period $t$. Under the null hypothesis of no long-term persistence, the estimate of $\beta_{h}$ at long horizons (such as $h=5$ or greater) should be zero.

To shed light on the effects of employment fluctuations on other labor market variables, we reestimate equation (1) with revisions to forecast of labor force participation and the unemployment rate as dependent variables and with revisions to current-period employment forecasts remaining as the explanatory variable. We conduct the estimation both for pooled multi-country panels and on a country-by-country basis. Our approach is close to that of Bluedorn and Leigh (2018) who conduct such tests for real GDP.

\section{B. Sample}

Forecasts of labor market variables over extended horizons going back several decades are available for numerous countries in the historical vintages of the IMF World Economic Outlook (WEO). Historical vintages of the WEO include the IMF staff forecasts of labor market variables over five-year-ahead horizons made in the Spring and Fall of every year. We compile all such forecasts starting with the vintage of the of Spring of 1990 and ending with the vintage of the Fall of 2018 for 34 advanced economies (AEs). In related work (Bluedorn and Leigh 2018) where we focus on long-term real GDP forecasts, we use private-sector forecasts collected by Consensus Economics. That data source includes historical forecasts for especially long (ten-year-ahead) horizons but does not include long-term forecast of labor market variables. For this reason, we focus on WEO forecasts. ${ }^{3}$

\footnotetext{
${ }^{3}$ Forecasts prepared by the U.S. Congressional Budget Office (CBO) include forecasts for labor market variables over ten-year ahead horizons for the United States. However, such long-range CBO forecasts for employment, labor
}

(continued...) 


\section{Baseline results}

Figure 1 reports our baseline results for 34 advanced economies. Our estimates suggest that forecasters view fluctuations in employment as typically having long-lasting effects. On average, following a 1 percent surprise increase in employment, forecasters adjust the five-year-ahead level forecast of employment up by more than one-for-one (by 1.6 percent) in the same direction. Forecasters thus do not typically expect employment expansions to be followed by slower growth and a return to (or even toward) the previous trend. Forecasters also revise up their five-year-ahead labor force participation forecast up by 1.1 percent and reduce their five-year-ahead unemployment rate forecast by 0.4 percentage point. The 90 percent confidence interval for the employment and labor force estimated responses are above 1.0, while that for the unemployment rate is below zero.

The results hold not only for the group of advanced economies on average, but also for major advanced economies considered individually. Figure 2 reports similar results for the United States, Canada, Japan, and the Euro Area. However, for such individual-economy results, the estimated confidence intervals are wider, reflecting the significantly reduced sample sizes. Averaging the country-level estimates using the Pesaran, Shin, and Smith (1999) mean group estimator yields an expected effect averaging 1.6 percent for the 34 advanced markets.

Overall, our baseline results are consistent with the notion that forecasters view economic expansions as typically having long-lasting positive effects on employment and labor force participation and persistently reducing the unemployment rate. Forecasters appear to have (at least implicitly) long-known the results emerging from recent studies on the long-lasting persistent effects of economic fluctuations. The results are less consistent with the traditional view of economic fluctuations where shocks typically have transitory effects. ${ }^{4}$

\section{Robustness}

The finding that forecasters expect labor market fluctuations to typically have strong and longlasting effects is highly robust, as we report in Table 1.

To address the potential concern that the results are driven by the global financial crisis and its aftermath, we first exclude all observations for 2007-2018 from the sample and find that the results barely change. Similarly, to investigate whether the results are driven by unusually large revisions to employment, we repeat the estimation based on a trimmed sample that excludes the largest 10 percent of current-period forecast revisions (in absolute value) from the sample. Again, the results are virtually unchanged compared with the full-sample baseline. We also find very similar results when excluding negative (contractionary) revisions to current-period employment from the

force participation and the unemployment rate are only available since 2011 . We compare our baseline results based on WEO with those obtained for $\mathrm{CBO}$ forecasts as a robustness check, finding consistent results.

${ }^{4}$ Our baseline results reflect all revisions to current-period employment, irrespective of the source of the revision. Some of the revisions could potentially reflect forecaster's changing views on demographic factors, such as immigration and population aging. We do not, however, have separate forecast revisions for demographic trends that would be needed to investigate these factors. 
sample, suggesting that forecasters view the effects of expansionary and contractionary shocks as approximately symmetric. To check if the results are driven by episodes where the economy is unusually far from its perceived long-term trend, we exclude periods in which forecasters' estimates of the current-period gap between unemployment and the natural rate of unemployment (also available in the historical vintages of the WEO) is in the top 10 percent (in absolute value) of the sample. Again, the results are similar to the baseline, suggesting that such cases are not driving the results.

We also consider the sensitivity of the results to controlling for additional variables in equation (1). We test the robustness of the results to controlling for time- and country-fixed effects, finding that the results are unchanged. We also examine how the results change if we control for the oneperiod lag of revision to current-period employment. This test addresses the possibility that current-period employment revision are correlated over time, due, for example, to gradual learning by forecasters regarding the state of the economy. Such correlation in current-period employment revisions could cause a positive bias to estimates of $\beta$ in equation (1). However, controlling for lagged forecast revisions leaves the results virtually unchanged.

Finally, we investigate if the results we obtain for forecasts taken from the IMF WEO are different than could be obtained for other sources of forecasts. As already mentioned, historical vintages of forecasts for labor-market variables including employment, the labor force, and the unemployment rate are not widely available for long-term forecast horizons. One exception is the set of 10 -Year Economic Projections prepared by the CBO for the United States, with ten-year-ahead forecasts of employment, the labor force and the unemployment rate. The CBO long-term projections for these variables are available on an annual or semi-annual basis since 2008, yielding 17 observations of forecast revisions. The results based on this sample of CBO forecast revisions are, as Figure 3 illustrate, consistent with those that we obtain for WEO forecasts for the United States although these are only available for up to the five-year-ahead forecast horizon. The CBO results suggest that, following an unexpected 1 percent rise in employment, forecasters raise long-term (ten-year-ahead) employment forecasts up by more than one-for-one and also significantly raise labor force participation forecasts. Forecasts for the unemployment rate now suggest a gradual return to the previous level over the long term, reflecting an expected partial moderation in employment combined with the expected rise in labor force participation.

\section{DEMAND-SIDE SHOCKS}

We now extend our analysis to assess the long-term effects of changes in aggregate demand. A standard implication of New Keynesian economic models is that positive shocks to aggregate demand induce a short-term trade-off between unemployment and inflation but have no long-term effects on economic activity, in line with Friedman's (1968) natural rate hypothesis.

We define periods featuring a dominant role for aggregate demand changes as those where forecasts of current-period unemployment and inflation based on information available in real time move unexpectedly in opposite directions. In particular, we include in the sample all periods in which forecasters revise forecasts of the unemployment rate in the current period down and contemporaneously revise forecasts of CPI inflation up, as well as periods featuring the opposite 
pattern with unemployment rising and inflation falling unexpectedly. The CPI inflation forecasts come, as for the other series, from the historical vintages of the WEO.

Our results, reported in Table 2, suggest that forecasters view economic expansions in such cases as also typically having long-lasting effects on employment, labor force participation, and the unemployment rate. For each 1 percent surprise in current-period employment in such episodes, the five-year-ahead forecast of employment rises by an average of 1.7 percent; the five-year-ahead forecast of labor force participation rises by 1.3 percent; and the five-year ahead forecast of the unemployment rate is 0.4 percentage point lower. These results continue to hold, as Table 2 reports, in episodes where, additionally, the economy is already assessed as being beyond full employment (based, as before, on the gap between the real-time estimates of the unemployment rate and the natural rate of unemployment). To shed light on the ongoing U.S. economic expansion, we repeat the estimation for U.S. data, finding similar results (Figure 4) although, given the much smaller sample available for such episodes in a single economy (in this case 13 observations), the results come with much wider confidence intervals.

The results also shed light on the anchoring of inflation expectations. As Figure 4 reports, for each 1 percent surprise in current-period employment, forecasters expect inflation to rise by an average of 0.2 percentage point. At the same time, as Figure 4 indicates, forecasters' expectations of inflation in 3-5 years are unaffected by the labor market shock, suggesting that their longer-term inflation expectations are firmly anchored in this sample. A further contributor to the expected reversion of inflation to its pre-shock level over the medium term could be that forecasters expect a decline in the natural rate of unemployment, implying a gradual closing of the unemployment gap (the difference between unemployment and its natural rate) from above, as the results reported in Figure 5 suggest.

To shed further light on the long-term effects of changes in aggregate demand, we also focus on episodes featuring large unexpected shifts in government consumption. In particular, we identify periods in which forecasters revised their forecast of government consumption and where the size of the revision was above the sample median (in absolute value). The government consumption forecasts come, as for the other series, from the historical vintages of the WEO. As Table 2 reports, the results for these episodes are similar to those identified based on the co-movement of inflation and unemployment. Our approach for identifying government spending shocks is similar to that of Auerbach and Gorodnichenko (2013) who define such shocks as the difference between ex-post government consumption and ex-ante forecasts of government from private-sector forecasts. For robustness, we repeat our analysis for episodes featuring large (above-median in absolute value) shocks taken from Auerbach and Gorodnichenko (2013) and, as Table 2 reports, find similar results. Finally, since government spending shocks can coincide with potentially offsetting changes in fiscal policy on the tax side, we repeat the analysis for episodes featuring large (abovemedian in absolute value) unexpected changes in the cyclically-adjusted overall fiscal balance based on the historical vintages of the WEO, again finding similar results.

Overall, these results support the notion that forecasters perceive expansions in economic activity associated with changes in aggregate demand as having long-term effects on labor market outcomes, even when the economy is already beyond full employment. The results for changes in government consumption are also broadly consistent with the findings of Fatás and Summers 
(2017) who argue that fiscal consolidation in advanced economies can have permanent effects on the supply-side of the economy.

\section{How Closely do Forecasters' Views of Persistence Fit the Data?}

If forecasters' views of long-term labor-market persistence are, on average, unbiased, then our approach sheds light on the actual persistence of shocks in the real economy. To investigate if this is the case, we investigate whether forecasters typically overestimate the long-term impact of employment fluctuations on labor market outcomes, or whether the true long-term impact of shocks is consistent with what forecasters expect.

We conduct a forecast efficiency test along the lines of Blanchard and Leigh (2013) which we have also used in related work (Bluedorn and Leigh 2018). We regress the forecast error for the level of each labor market variable in five years on the revision to current-period employment made in the period where the forecast is made. Under rational expectations, revisions to currentperiod employment known at the time forecasts are made should be orthogonal to subsequent forecast errors. If, on the other hand, forecasters systematically overstate the long-term impact of current-period employment fluctuations, there should be a negative relation between revisions to current-period employment known at the time forecasts are made and subsequent forecast errors. We find limited evidence of this.

The equation we estimate is:

$$
x_{i, t+h}-f_{t}\left(x_{i, t+h}\right)=\alpha+\theta r_{t}\left(e_{i, t}\right)+\varepsilon_{h, i, t}
$$

where $x_{i, t+h}$ denotes the actual realization of each labor market variable $x$ (employment, labor force, and unemployment, respectively) in $h=5$ years; $f_{t}\left(x_{i, t+h}\right)$ denotes the forecast of that variable made in period $t$; and $r_{t}\left(e_{i, t}\right)$ denotes the forecast revision to the forecast for employment in period $t$ made based on real-time information available within period $t$. The term $x_{i, t+h}-$ $f_{t}\left(x_{i, t+h}\right)$ is thus the $h$-year ahead forecast error. The equation estimated is identical to equation (1) except that the left-hand side is now the five-year-ahead output forecast error rather than the revision to the five-year-ahead forecast. The null hypothesis consistent with rational expectations is $\theta=0$. If on the other hand forecasters overstate the persistence of shocks, the estimate of $\theta$ should be negative. The coefficient $\theta$ can additionally be interpreted as the gap between assumed and actual long-term persistence.

As Table 3 reports, we find little evidence of a systematic correlation between long-term forecast errors and current-period shocks. The estimate of $\theta$ is positive but statistically indistinguishable from zero for employment forecasts; positive and statistically significant in the case of labor force participation forecasts; and near zero and statistically indistinguishable from zero for the unemployment rate. These results suggest that forecasters neither over- nor understate the longterm impact of shocks on employment and the unemployment rate and that the long-term effects of shocks on labor force participation are somewhat stronger than forecasters expect. The lack of a systematic negative correlation between long-term forecast errors and current-period shocks is 
also evident in the scatter plots in Figure $6 .^{5}$ This result holds both for the panel of advanced economies and-based on a significantly smaller number of available observations-for individual major advanced economies such as the United States.

We conclude that forecasters' views of long-term persistence of labor market variables are, on average, unbiased, and thus informative regarding the actual long-term effects of shocks. Actual persistence of labor market variables is likely to be consistent with (or somewhat stronger than) perceived long-term persistence. These results are also consistent with the results of Bluedorn and Leigh (2018) for long-term real GDP forecasts from Consensus Economics.

\section{Conclusion}

Taken together, our findings of persistence in forecast revisions and of forecasts of persistence being unbiased suggest that demand-driven labor market booms generate longer-lasting effects on labor market outcomes than traditionally assumed. Our results are consistent with the presence of positive hysteresis - aggregate demand shocks may have effects on aggregate supply — and run counter to the view that long-run outcomes are independent of aggregate demand.

What do the results imply for the conduct of aggregate demand policies and monetary policy in particular? Further research on mechanisms linking aggregate demand policy actions with hysteresis is needed, but we believe our results support the following preliminary conclusions.

First, if, as our results suggest, the costs of recessions are more long-lasting than traditionally assumed, this implies the need for an especially timely and strong monetary policy response. There may be little value in keeping powder dry. Monetary policy easing early on, possibly complemented with countercyclical fiscal policies, can mitigate long-lasting negative effects on labor force participation and employment prospects.

Second, the benefits of economic booms are also longer lasting than traditionally assumed. Positive longer-term effects may arise from tight labor markets drawing discouraged workers back into the labor force, encouraging more efficiency-enhancing job switches, and prompting more investment into human capital through on-the-job training as well as complementary investments into physical capital and research and development.

In this case, maintaining an accommodative monetary policy stance and allowing labor market markets to be tighter may result in positive long-term supply-side benefits. The challenge for policymakers is to judge when this margin of "hidden slack" may be exhausted and when such policy accommodation may raise risks to inflation and financial stability. This is no easy task. Moreover, our results indicate that inflation expectations have been well-anchored in the face of

\footnotetext{
${ }^{5}$ A possible concern with the results in Table 3 is that the current-period employment shocks perceived in real time, which appear on the right-hand side of equation (2) and are denoted by $r_{t}\left(e_{i, t}\right)=f_{t}\left(e_{i, t}\right)-f_{t-1}\left(e_{i, t}\right)$, may systematically differ from the actual ex-post (forecast error) shocks, $e_{i, t}-f_{t-1}\left(e_{i, t}\right)$, and that such a difference could influence the results. To investigate this possibility, we regress the ex-post forecast errors on the revisions, that is, we estimate the equation $e_{i, t}-f_{t-1}\left(e_{i, t}\right)=\alpha+\beta\left(f_{t}\left(e_{i, t}\right)-f_{t-1}\left(e_{i, t}\right)\right)+\varepsilon_{i, t}$. The estimate of $\beta$ is 0.99 (s.e. $=0.07$ ), implying that ex-post shocks to employment are strongly correlated with the shocks perceived in real time.
} 
demand-driven booms in our sample of advanced economies since the 1990s, but this could cease to be the case if policymakers seek to perennially exploit the trade-off between inflation and unemployment without regard to the potential limits to positive hysteresis. Policymakers must carefully weigh these various costs and benefits in coming to a decision on the appropriate policy stance. 


\section{References}

Aaronson, Stephanie R., Mary C. Daly, William Wascher, and David W. Wilcox, 2019. "Okun Revisited: Who Benefits Most from a Strong Economy?” Brookings Papers on Economic Activity Conference Draft, March 2019.

Auerbach, Alan J., and Yuriy Gorodnichenko, 2013. "Output Spillovers from Fiscal Policy." American Economic Review, Vol. 103(3), May 2013, pp. 141-46.

Ball, Laurence, 2009. "Hysteresis in Unemployment: Old and New Evidence." NBER Working Paper No. 14818 (March 2009).

Ball, Laurence, 2014. "Long-term damage from the Great Recession in OECD countries.” NBER Working Paper No. 20185.

Blanchard, Olivier J., 2018. "Should We Reject the Natural Rate Hypothesis?" Journal of Economic Perspectives, 32, pp. 97-120.

Blanchard, Olivier, Eugenio Cerutti, and Lawrence Summers, 2015. "Inflation and Activity - Two Explorations and their Monetary Policy Implications." NBER Working Paper No. 21726.

Blanchard, Olivier J., and Daniel Leigh, 2013. "Growth Forecast Errors and Fiscal Multipliers," American Economic Review, vol. 103(3), pages 117-20, May.

Bluedorn, John, and Daniel Leigh, 2018. "Is the Cycle the Trend? Evidence from the Views of International Forecasters.” IMF Working Paper No. 18/163.

Coibion, Olivier, Yuriy Gorodnichenko, and Rupal Kamdar, 2018. "The Formation of Expectations, Inflation, and the Phillips Curve." Journal of Economic Literature, Vol 56(4), pages 1447-1491.

Erceg, Christopher J., Andrew Levin, 2014. "Labor Force Participation and Monetary Policy in the Wake of the Great Recession." Journal of Money, Credit and Banking, Vol. 46 (2).

Fatás, Antonio, and Lawrence H. Summers, 2018. "The Permanent Effects of Fiscal Consolidations." Journal of International Economics, Volume 112, May 2018, Pages 23825.

Friedman, Milton, 1968. "The Role of Monetary Policy." Presidential address delivered at the $80^{\text {th }}$ Annual Meeting of the American Economic Association. American Economic Review 58(1): 1-17.

Krane, Spencer D., 2011. "Professional Forecasters' View of Permanent and Transitory Shocks to GDP.” American Economic Journal: Macroeconomics, Vol. 3, pp. 184-211.

Hotchkiss, Julie L. and Robert E. Moore, 2018. "Some Like It Hot: Assessing Longer-Term Labor Market Benefits from a High-Pressure Economy." Federal Reserve Bank of Atlanta Working Paper 2018-1.

Martin, Robert, Teyanna Munyan, and Beth Anne Wilson. 2015. "Potential Output and Recessions: Are We Fooling Ourselves?" Federal Reserve Board International Finance Discussion Papers no. 1145.

Okun, Arthur M., 1973. "Upward Mobility in a High-pressure Economy." Brookings Papers on Economic Activity, 1:1973.

Pesaran, M. Hashem, Yongcheol Shin and Ron P. Smith, 1999. "Pooled Mean Group Estimation of Dynamic Heterogeneous Panels." Journal of the American Statistical Association, Vol. 94, No. 446 (Jun., 1999), pp. 621-634. 
Powell, Jerome H., 2018. "Monetary Policy at a Time of Uncertainty and Tight Labor Markets." Speech at "Price and Wage-Setting in Advanced Economies," an ECB Forum on Central Banking, Sintra, Portugal.

Yagan, Danny, 2018. "Employment Hysteresis from the Great Recession.” NBER Working Paper No. 23844.

Yellen, Janet L., 2016. "Macroeconomic Research After the Crisis." Speech at "The Elusive 'Great' Recovery: Causes and Implications for Future Business Cycle Dynamics" 60th annual economic conference sponsored by the Federal Reserve Bank of Boston, Boston, Massachusetts. October 14, 2016. 


\section{Figure 1. Estimated Perceived Responses to a 1 Percent Shock to Employment}
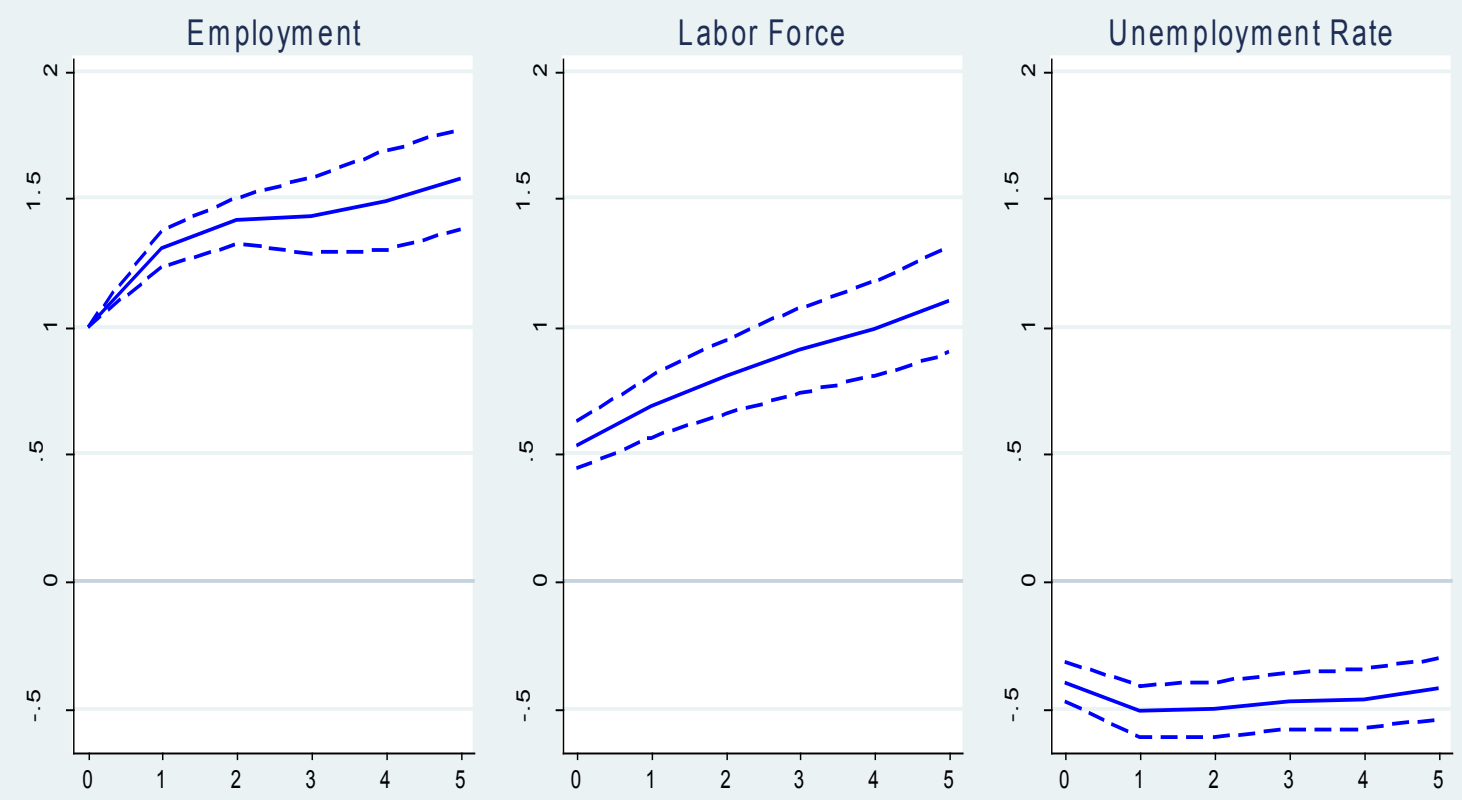

Note: Years on x-axis. Units are in percent for employment and labor force, and in percentage points for unemployment rate. Figure reports estimated perceived impulse responses based on revisions to professional forecasts. Dashes indicate 90 percent confidence intervals. 
Figure 2. Selected Economies: Estimated Perceived Responses to a 1 Percent Shock to Employment

\section{United States}
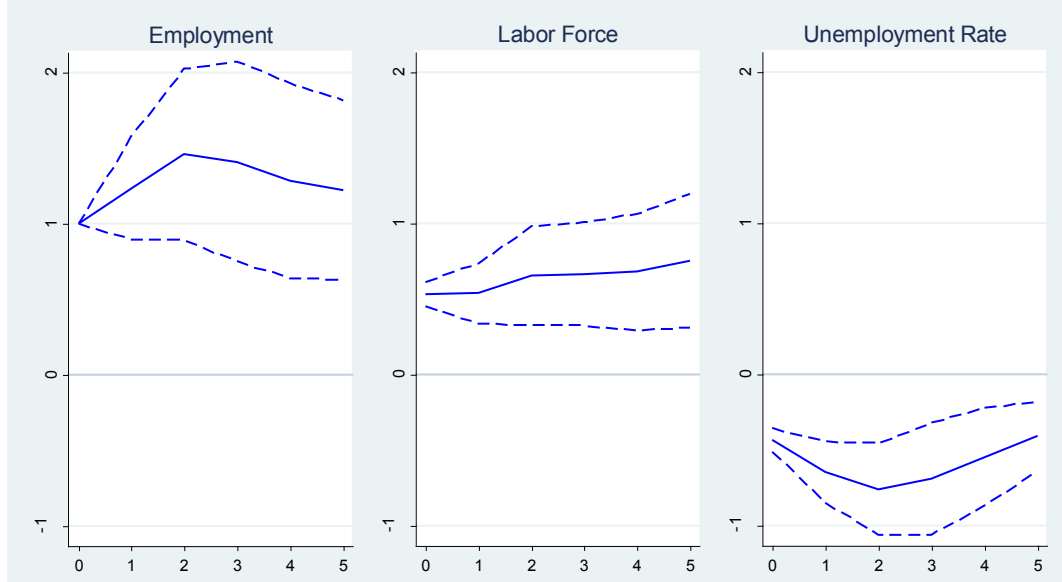

3. Japan
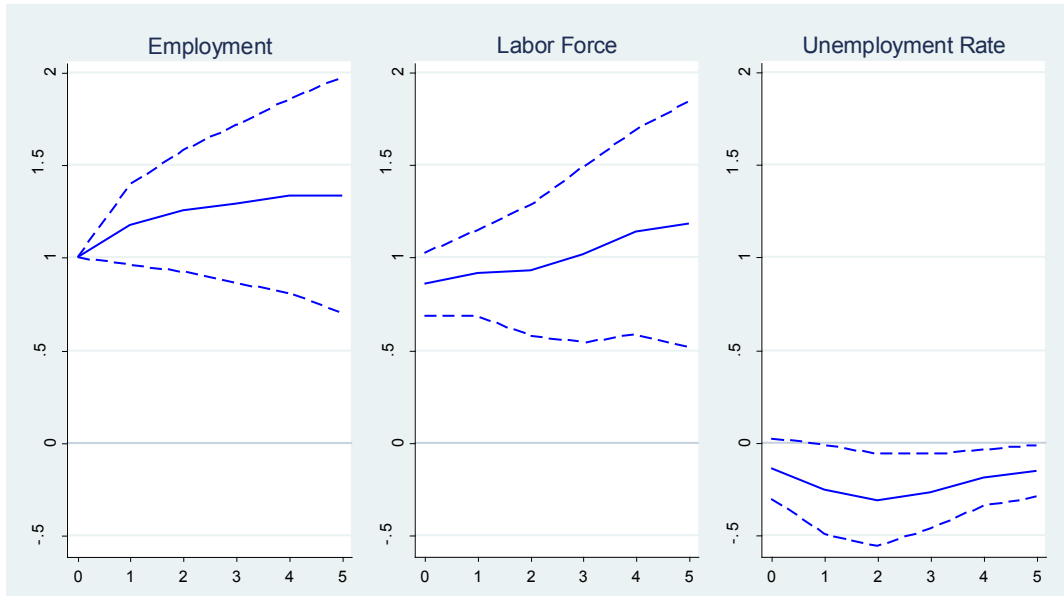

2. Canada
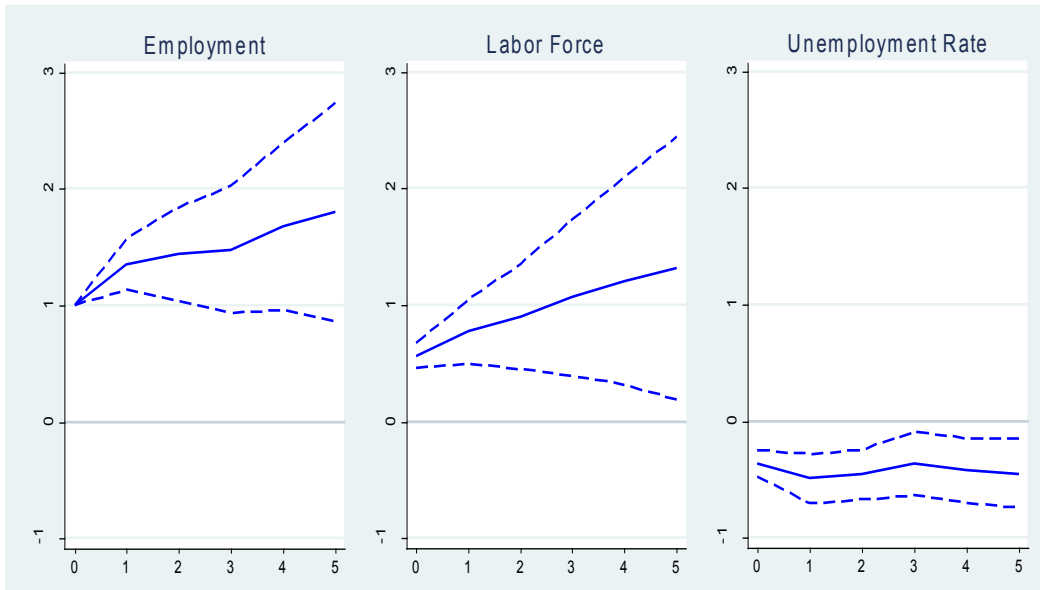

3. Euro Area
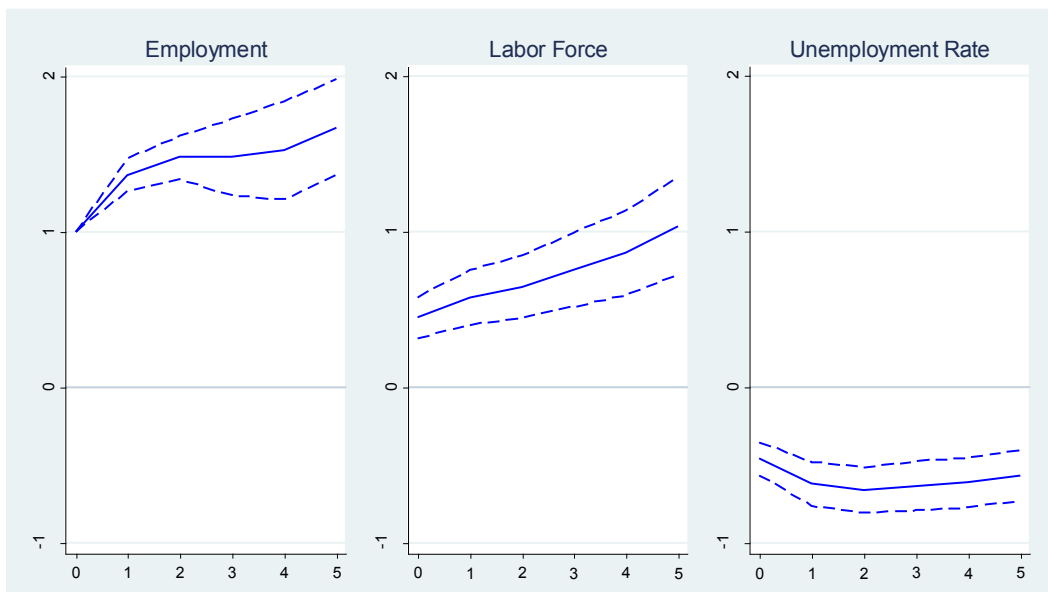

Note: Years on x-axis. Figure reports estimated perceived impulse responses based on revisions to professional forecasts. Dashes indicate 90 percent confidence intervals. 
Figure 3. United States: Comparison of Results for Congressional Budget Office and World Economic Outlook Forecast Revisions

Estimated Perceived Responses to a 1 Percent Shock to Employment

(Based on annual or semi-annual revisions since 2008)

A. United States: Congressional Budget Office
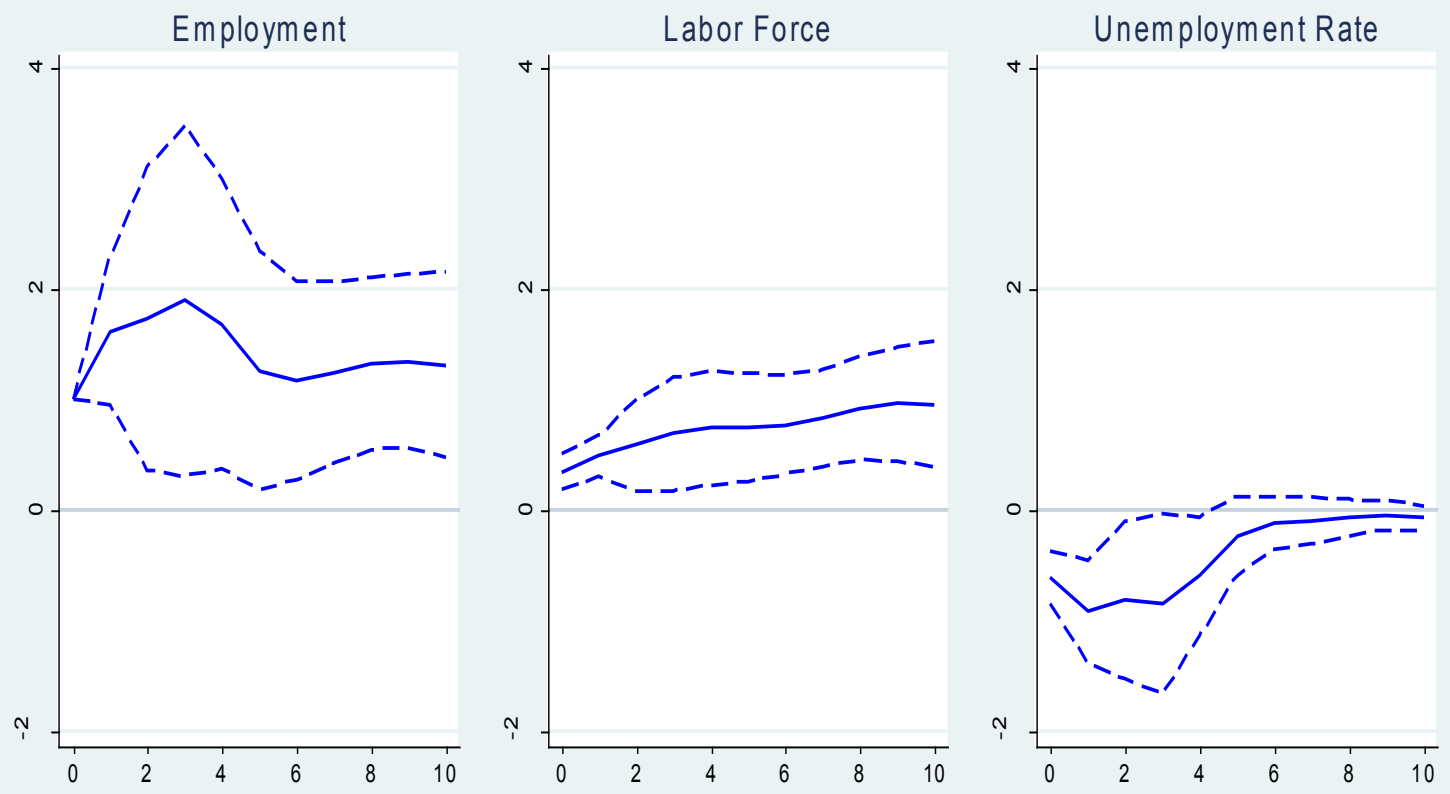

B. United States: World Economic Outlook
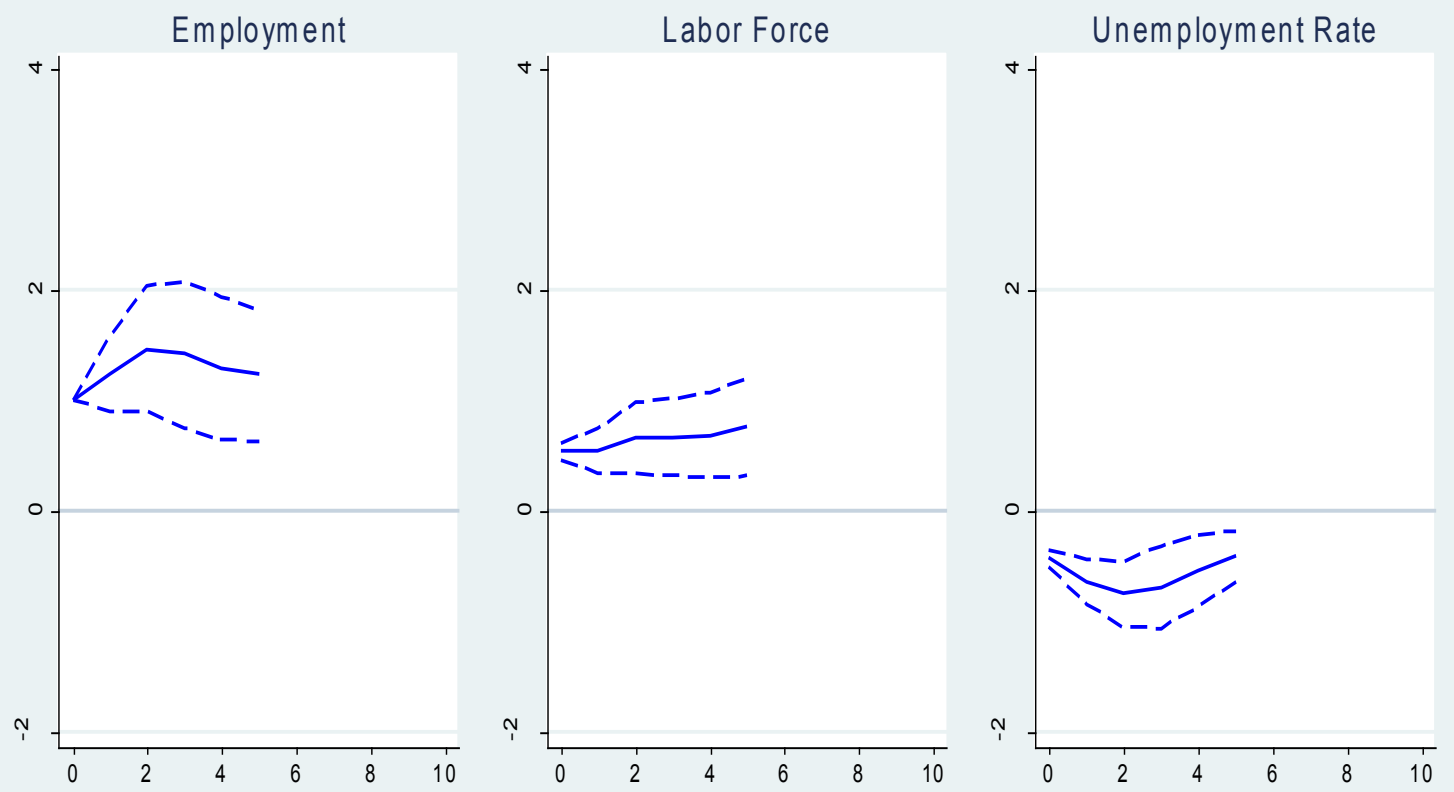

Note: Years on x-axis. Figure reports estimated perceived impulse response based on revisions to professional forecasts. Dashes indicate 90 percent confidence intervals. 
Figure 4. Episodes Associated with Changes in Aggregate Demand

Estimated Perceived Responses to a 1 Percent Shock to Employment

\section{A. Full Sample}

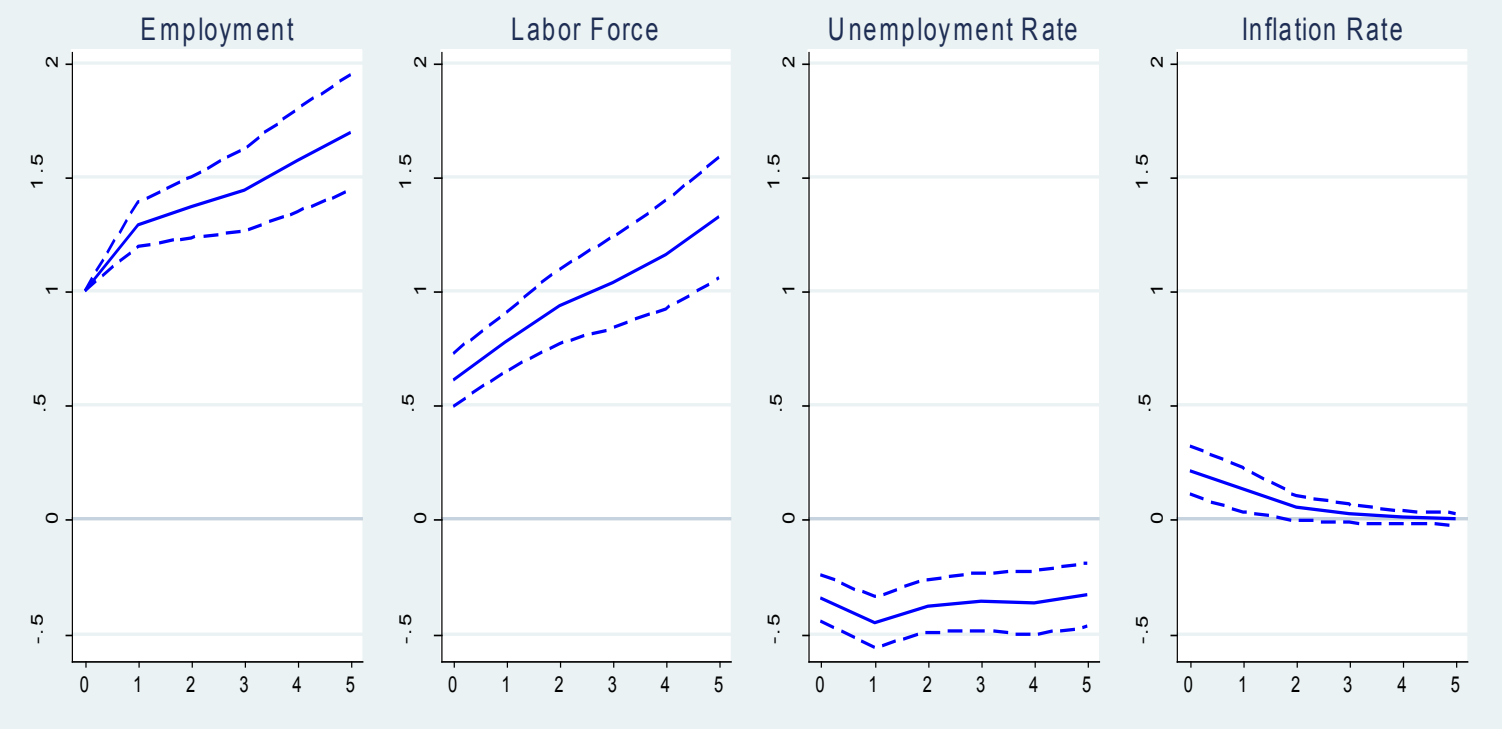

B. United States
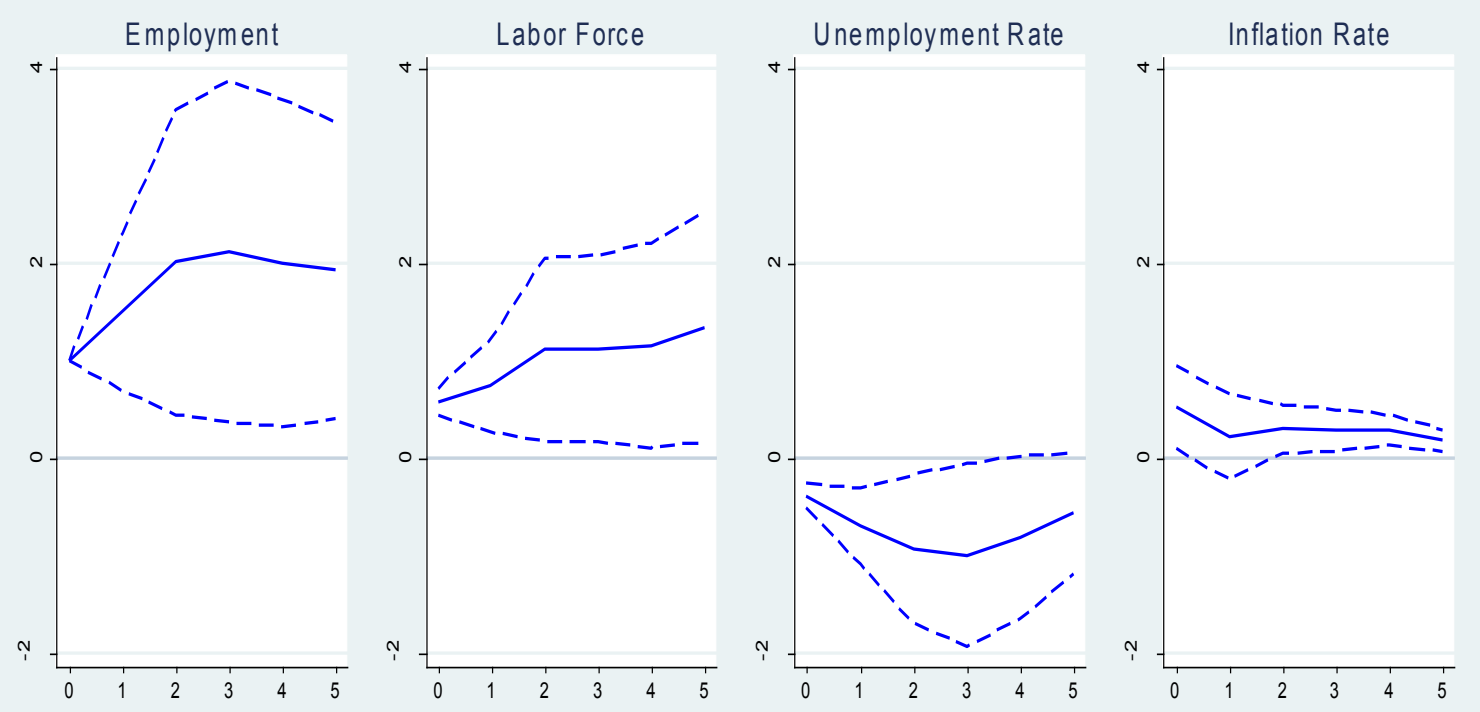

Note: Years on x-axis. Units are in percent for employment and labor force, and in percentage points for unemployment rate and inflation rate. Figure reports estimated perceived impulse responses based on revisions to professional forecasts. Dashes indicate 90 percent confidence intervals. 
Figure 5. Episodes Associated with Changes in Aggregate Demand: Unemployment Gap Estimated Perceived Responses to a 1 Percent Shock to Employment
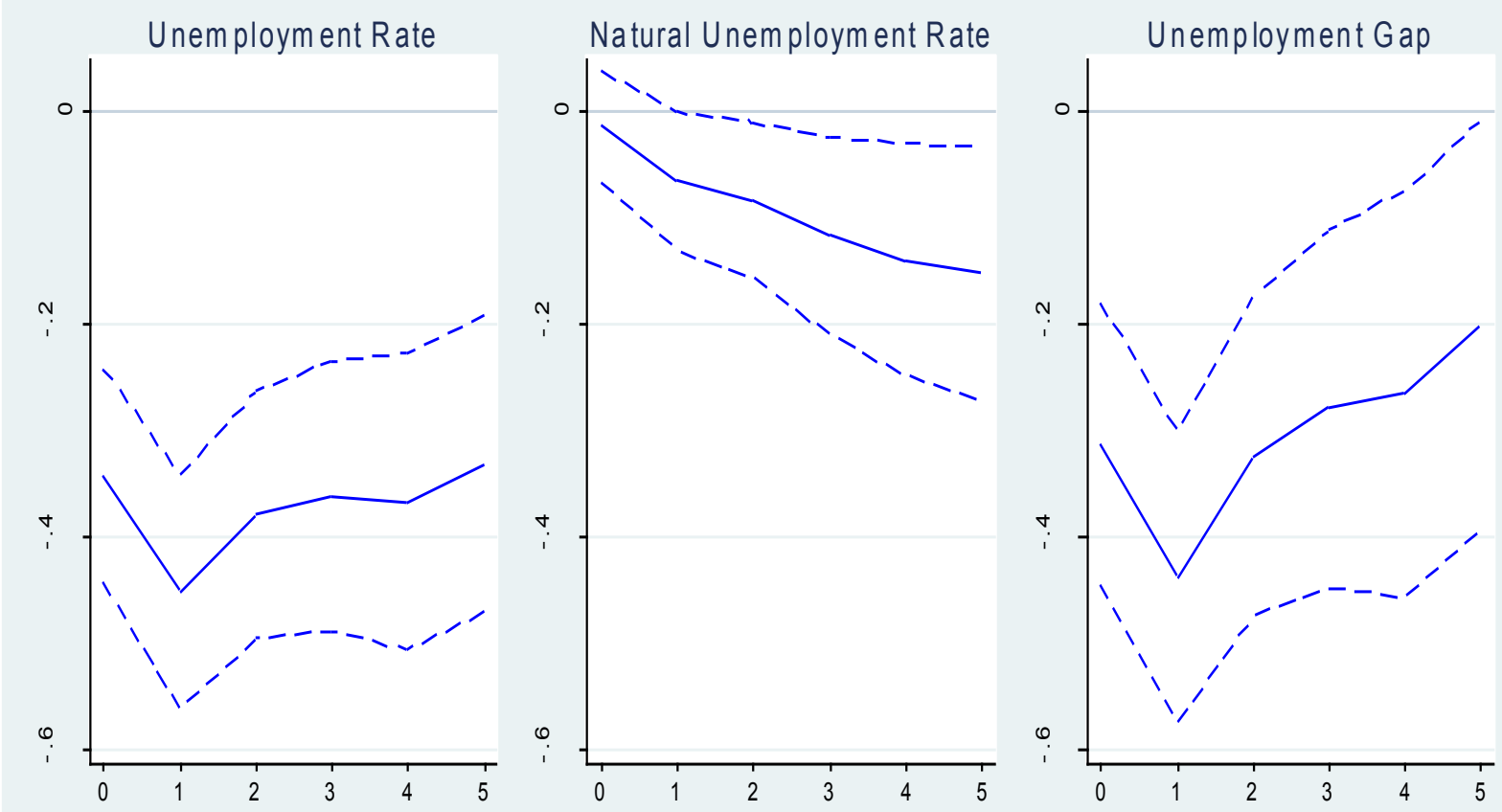

Note: Years on $\mathrm{x}$-axis. Units are in percentage points. Figure reports estimated perceived impulse responses based on revisions to professional forecasts. Dashes indicate 90 percent confidence intervals. 
Figure 6. Forecast Evaluation: Long-term Forecast Errors vs. Current-period Forecast Revisions of Employment

A. Full Sample
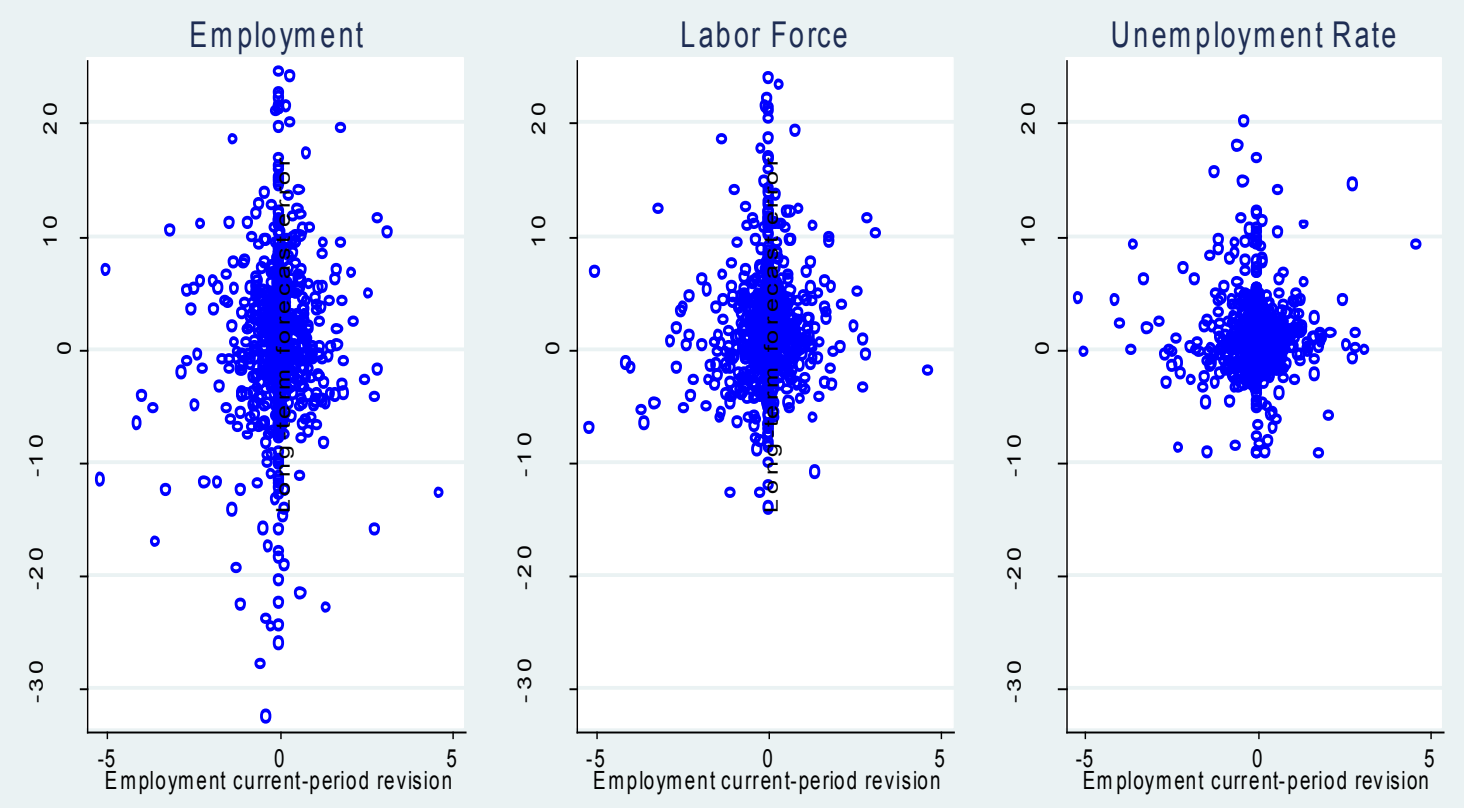

B. Sample of Demand-side Shocks
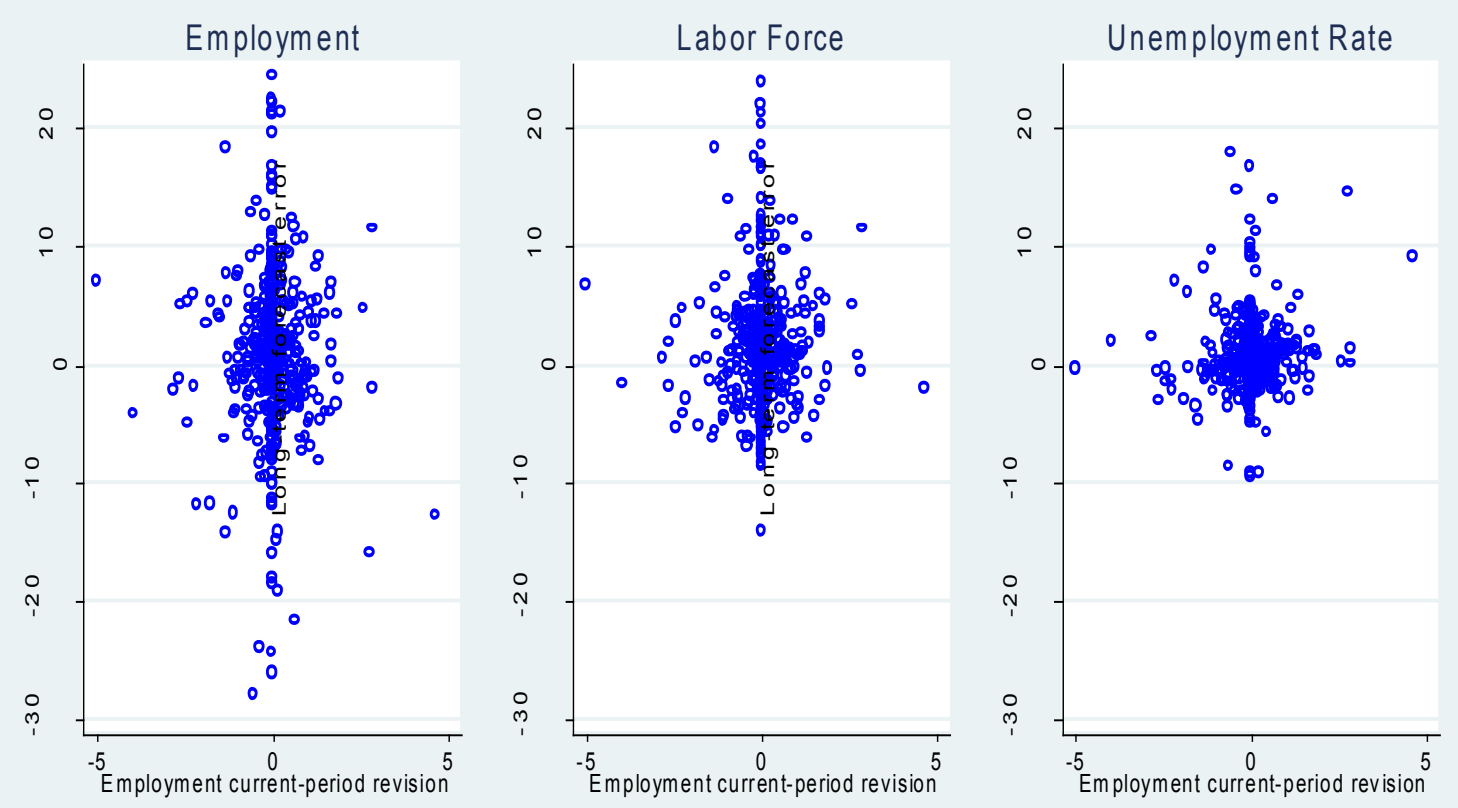

Note: Units are in percentage points. Sample ends in 2013, last forecast error is for level in 2018 made in 2013. 
Table 1. Robustness

(Point estimate; standard error; number of observations)

Equation estimated: $r_{t}\left(x_{i, t+h}\right)=\alpha+\beta_{h} r_{t}\left(e_{i, t}\right)+\varepsilon_{h, i, t}$

\begin{tabular}{|c|c|c|c|}
\hline & Employment & Labor Force & Unemployment Rate \\
\hline \multirow[t]{3}{*}{ Full sample (baseline) } & 1.58 & 1.10 & -0.42 \\
\hline & $(0.12)$ & $(0.13)$ & $(0.07)$ \\
\hline & 945 & 944 & 946 \\
\hline \multirow[t]{3}{*}{ Pre-2007 sample } & 1.56 & 1.12 & -0.39 \\
\hline & (0.19) & $(0.20)$ & $(0.10)$ \\
\hline & 538 & 537 & 539 \\
\hline \multirow[t]{3}{*}{ Trimmed sample } & 1.44 & 1.08 & -0.35 \\
\hline & $(0.14)$ & $(0.14)$ & $(0.07)$ \\
\hline & 851 & 850 & 852 \\
\hline \multirow[t]{3}{*}{ Excluding contractions } & 1.71 & 1.29 & -0.37 \\
\hline & $(0.17)$ & $(0.18)$ & $(0.10)$ \\
\hline & 605 & 605 & 605 \\
\hline \multirow{3}{*}{$\begin{array}{l}\text { Excluding large deviations } \\
\text { from full employment }\end{array}$} & 1.64 & 1.35 & -0.25 \\
\hline & $(0.13)$ & $(0.15)$ & $(0.07)$ \\
\hline & 624 & 624 & 624 \\
\hline \multirow[t]{3}{*}{ Controlling for country fixed effects } & 1.58 & 1.10 & -0.42 \\
\hline & $(0.12)$ & $(0.15)$ & $(0.10)$ \\
\hline & 945 & 944 & 946 \\
\hline \multirow[t]{3}{*}{ Controlling for lagged revisions } & 1.54 & 1.11 & -0.38 \\
\hline & $(0.13)$ & $(0.14)$ & $(0.07)$ \\
\hline & 832 & 832 & 832 \\
\hline
\end{tabular}

Note: Table reports estimates of perceived effect on each variable in $h=5$ years. Percent for employment and labor force; percentage points for unemployment rate. Deviation from full-employment denotes forecasters' estimates of current-period unemployment rate in deviation from forecasters' estimates of natural unemployment rate (in same forecast vintage). 
Table 2. Demand-side Shocks

Perceived Long-term Effect of a 1 Percent Shock to Employment on Labor Market Variables (Point estimate; standard error; number of observations)

Equation estimated: $r_{t}\left(x_{i, t+h}\right)=\alpha+\beta_{h} r_{t}\left(e_{i, t}\right)+\varepsilon_{h, i, t}$

\begin{tabular}{lccc}
\hline \hline & Employment & Labor Force & Unemployment Rate \\
\hline Sample with inflation and unemployment in year $t$ & 1.69 & 1.31 & -0.34 \\
moving unexpectedly in opposite directions & $(0.16)$ & $(0.16)$ & $(0.09)$ \\
& 405 & 404 & 405 \\
Sample with inflation and unemployment in year $t$ & 1.70 & 1.27 & -0.41 \\
moving unexpectedly in opposite directions & $(0.30)$ & $(0.26)$ & $(0.16)$ \\
and economy beyond full employment. & 98 & 98 & 98 \\
& & & -0.52 \\
WEO government consumption shocks & 1.76 & 1.18 & $(0.14)$ \\
& $(0.22)$ & $(0.25)$ & 199 \\
Auerbach-Gorodnichenko government shocks & 199 & 199 & -0.30 \\
& 1.42 & 1.05 & $(0.15)$ \\
WEO structural balance shocks & $(0.15)$ & $(0.16)$ & 229 \\
& 229 & 229 & -0.64 \\
& & & $(0.18)$ \\
\end{tabular}

Note: Economy beyond full employment defined as periods in which forecasters' estimates of current-period unemployment rate is below forecasters' contemporaneous estimates of natural unemployment rate. Table reports estimates of perceived effect on each variable in $h=5$ years. Percent for employment and labor force; percentage points for unemployment rate. Table reports point estimates, robust standard errors in parentheses, and number of observations. 
Table 3. Forecast Evaluation: Estimation Results

Equation estimated: $\quad x_{i, t+h}-f_{t}\left(x_{i, t+h}\right)=\alpha+\theta r_{t}\left(e_{i, t}\right)+\varepsilon_{h, i, t}$

A. Full Sample

\begin{tabular}{lccc}
\hline \hline & \multicolumn{3}{c}{ Long-term forecast error } \\
\cline { 2 - 4 } Variable $(x)$ & Employment & Labor Force & Unemployment Rate \\
$\theta$ & 0.51 & 0.50 & 0.01 \\
& $(0.35)$ & $(0.22)$ & $(0.18)$ \\
Constant & & & 0.92 \\
& 0.56 & 1.60 & $(0.12)$ \\
Observations & $(0.25)$ & $(0.18)$ & 774 \\
R-squared & 773 & & 0.000 \\
\hline
\end{tabular}

B. Sample with Demand-side Shocks

\begin{tabular}{lccc}
\hline \hline & \multicolumn{3}{c}{ Long-term forecast error } \\
\cline { 2 - 4 } Variable $(x)$ & Employment & Labor Force & Unemployment Rate \\
$\theta$ & -0.18 & 0.24 & 0.39 \\
& $(0.42)$ & $(0.27)$ & $(0.22)$ \\
Constant & 0.76 & & 0.87 \\
& $(0.33)$ & 1.76 & $(0.15)$ \\
Observations & 430 & 430 & 430 \\
R-squared & 0.000 & 0.001 & 0.010 \\
\hline
\end{tabular}

Note: Table reports estimates for $h=5$ years. Percent for employment and labor force; percentage points for unemployment rate. Table reports point estimates, robust standard errors in parentheses. 